\title{
Post-operative Anemia After Major Surgery: a Brief Review
}

\author{
Smita K. Kalra ${ }^{1}$ (i) $\cdot$ Bright Thilagar $^{2} \cdot$ Maleka Khambaty $^{3} \cdot$ Efren Manjarrez $^{4}$
}

Accepted: 14 May 2021 / Published online: 16 June 2021

(C) The Author(s) 2021

\begin{abstract}
Purpose of Review Anemia is a very common complication in the post-operative period. Post-operative anemia is associated with poor outcomes including but not limited to infections, increased length of stay, circulatory overload, and mortality. The strategy of patient blood management focuses on three pillars that include the detection and treatment of pre-operative anemia; reduction of peri-operative blood loss; and harnessing and optimizing the patient-specific physiological reserve of anemia.

Recent Findings Multiple studies in surgical patients have been conducted to study various methods of management of postoperative anemia. Recent advances in surgical techniques have also been studied to minimize blood loss. There is a widespread consensus on the use of intravenous iron in hospitalized post-operative patients after major surgery.

Summary We discuss the most common causes of post-operative anemia and management focusing on measures to reduce blood loss and measures to increase red blood cell (RBC) mass. In this brief review, we present updates from the most relevant articles in the past 5 years and include updates from the 2018 international consensus statement on the management of post-operative anemia after major surgical procedures.
\end{abstract}

Keywords Anemia . Post-operative anemia - Peri-operative anemia - Intravenous iron P Post-operative evaluation . Peri-operative care

\section{Introduction}

Anemia is a very common complication in the post-operative period after a major surgery. The World Health Organization (WHO) defines anemia as a hemoglobin (Hgb) of $<13 \mathrm{~g} / \mathrm{dL}$ for men and $<12 \mathrm{~g} / \mathrm{dL}$ for women. Post-operative anemia is associated with poor outcomes including but not limited to infections, increased length of stay, circulatory overload, and mortality. Prevalence of post-operative anemia can be in the

Smita K. Kalra

smitakohli@gmail.com

1 Division of Hospital Medicine, University of California Irvine Medical Center, 333 City Blvd W, Ste 500, 101 The City South Dr, Orange, CA 92868, USA

2 Division of Hospital Medicine, Henry Ford Hospital, 2799 West Grand Blvd, Detroit, MI 48202, USA

3 Division of General Internal Medicine, University of Minnesota, 420 Delaware St SE, Minneapolis, MN 55455, USA

4 Division of Hospital Medicine, University of Miami Miller School of Medicine, 1120 NW 14 St, CRB 1130, Miami, FL 33136, USA range of 80-90\% after major surgery [1]. Understanding the cause of the anemia is the key to management of postoperative anemia. The concept of patient blood management (PBM) was introduced in 2005 and is being utilized in healthcare institutions worldwide. This strategy focuses on three pillars: the detection and treatment of pre-operative anemia; reduction of peri-operative blood loss; and harnessing and optimizing the patient-specific physiological reserve of anemia (including restrictive hemoglobin transfusion triggers) [2]. In this brief review, we discuss the most common causes of post-operative anemia and present updates from the most relevant articles in the management of post-operative anemia in the past 5 years.

\section{Causes of Post-operative Anemia}

Post-operative anemia after major non-cardiac surgeries may be due to worsening of pre-operative anemia, peri-operative blood loss (intra-operative blood loss, coagulopathy, and phlebotomy), and post-operative reduced erythropoiesis due to surgery-associated inflammation. Inflammatory cytokines after surgery can lead to a cascade of effects where increased hepcidin degrades the iron exporter ferroportin causing iron 
sequestration in macrophages. Active inflammation also leads to decreased iron uptake from the gastrointestinal tract and a diminished erythroid response to erythropoietin. This results in delayed recovery of hemoglobin post-operatively. Patients with cancer are at specially increased risk of bleeding due to multiple factors which include activation of procoagulant and antifibrinolytic pathways, effects of chemotherapy leading to anemia, thrombocytopenia and endothelial dysfunction, and, in some cases, close proximity or invasion into vasculature as well as hypervascularization of tumor itself [3]. Other factors are hemodilution from excessive peri-operative fluids (which may exacerbate pre-existing anemias), nutritional deficiencies, and pharmacological interactions. Low pre-operative hemoglobin, female sex, and smaller body surface area have been identified as risk factors for the development of postoperative anemia and increased transfusion needs [4]. An estimation of surgical blood loss after common surgeries is summarized in Table 1 [5].

Ongoing post-operative blood loss can continue through drains or into traumatized tissue, or due to repeated phlebotomy during prolonged post-operative hospitalization. As such, peri-operative blood loss may result in acute or late postoperative anemia. In general, hospitalists may consider the more common and major causes of anemia in surgical patients: iron deficiency anemia, anemia of chronic disease, and macrocytic anemia (of which vitamin B12 and folate deficiencies account for more than $95 \%$ of cases).

\section{Management of Post-operative Anemia}

The management of post-operative anemia should focus on correction and optimization of pre-operative anemia and hematinic deficiencies as well as preventing intra-operative blood loss. Ideally, this process should be started several weeks pre-operatively.

Measures to Reduce Blood Loss There are several medical, surgical, and anesthesia measures that can reduce the occurrence of post-operative anemia. Careful medication management helps minimize bleeding peri-operatively. This includes appropriate hold times for antiplatelets and anticoagulants. Medications like antiinflammatory agents, selective serotonin reuptake inhibitors, gingko, ginseng, and garlic interfere with hemostasis and should be held prior to surgery. Drugs such as amiodarone, fluconazole, rifampin, and phenytoin interact with direct oral anticoagulants (DOAC's) and can increase bleeding risk. The use of inappropriate bridging anticoagulation has been associated with increased peri-operative bleeding [6]. Restarting antiplatelet and anticoagulant medications prior to achieving hemostasis also increases peri-operative blood loss. The American College of Cardiology (ACC) consensus guidelines for peri-operative anticoagulation management in non-valvular atrial fibrillation recommend careful consideration of bleeding consequences, especially with high-risk bleeding procedures such as open cardiac, intracranial, and/or spinal procedures [7]. The ACC guidelines also include consideration of patient-specific factors that may predispose to bleeding complications (like bleeding diathesis, platelet dysfunction, antiplatelet medication). Following procedures with a low risk of post-procedural bleeding, therapeutic anticoagulation can generally be started within $24 \mathrm{~h}$ of surgery in collaboration with a proceduralist. However, following procedures with high bleeding risk, therapeutic parenteral anticoagulation or DOAC use should be delayed for at least $48-72 \mathrm{~h}$ after the procedure [7]. Table 2 summarizes the bleeding risk associated with commonly performed procedures $[8,9]$. Foregoing daily phlebotomy in stable patients decreases iatrogenic anemia and is not associated with increased readmissions or mortality. Every $100 \mathrm{~mL}$ of phlebotomy is associated with a hematocrit decrease of $1.9 \%$ [10].

Combined with modern blood management protocols, acute normovolemic hemodilution (ANH) and cell salvage are only beneficial in high bleeding risk $(>1000 \mathrm{~mL}$ ) surgeries. ANH is the donation of whole blood immediately prior to surgery with the use of colloid or crystalloid fluids to maintain a hematocrit of around 20-30\% [11]. Subsequently, less blood is lost during surgery, and donated blood is returned to the patient at wound closure. Cell salvage involves the collection of shed blood during surgery and the return of washed or filtered blood to the patient [2]. Although cell salvage is cost-effective compared to blood transfusion, its efficacy can be reduced by simultaneous use of antifibrinolytic and hemostatic agents. Potential harms from cell salvage include reintroduction of bacteria and malignant cells from contaminated field.

Another routinely used intra-operative technique is surgical drains. Drains can decrease compression of vital structures and reduce hematomas. However, the use of drains is controversial due to concern for increased bleeding. When they are used, clamping of drains 4 to $6 \mathrm{~h}$ post-operatively may reduce blood loss [12].

Antifibrinolytic agents like the synthetic lysine analog tranexamic acid (TXA) reduce blood loss by inhibiting activation of plasminogen to plasmin and preventing the degradation of fibrin. It is safe and effective in intravenous and topical forms with no increase in thromboembolism rates $[12,13]$. It has been shown to be efficacious and recommended for use with high bleeding risk surgeries like hip and knee replacements [14] as well as cardiac surgeries [15].

Neuraxial anesthesia can decrease bleeding by $20-30 \%$ through systemic hypotension and decrease in venous tone due to sympathetic blockade [2, 11]. Hypothermia, acidosis, and hypocalcemia inhibit hemostasis due to impaired platelet function and enzymatic clotting factors and thus should be avoided. Patient positioning to reduce obstruction of venous return also decreases local bleeding $[2,11]$. 
Table 1 Estimated blood loss with common major surgeries [5]

\begin{tabular}{|c|c|c|}
\hline \multicolumn{2}{|l|}{ Common surgical procedures } & \multirow{2}{*}{$\begin{array}{l}\text { Estimated blood loss } \\
200-1000 \mathrm{~mL}\end{array}$} \\
\hline & Shoulder arthroplasty & \\
\hline \multirow[t]{4}{*}{ Orthopedic surgeries } & Total knee arthroplasty: primary; revision & $300-500 \mathrm{~mL} ; 500-1000 \mathrm{~mL}$ \\
\hline & Total hip arthroplasty: primary; revision & $250-750 \mathrm{~mL} ;>1000 \mathrm{~mL}$ \\
\hline & Acetabular fracture open repair & $100-2000 \mathrm{~mL}$ \\
\hline & Hip fracture repair & $100-500 \mathrm{~mL}$ \\
\hline \multirow[t]{6}{*}{ Neurosurgical surgeries } & Cervical/lumbar laminectomy & $25-500 \mathrm{~mL}$ \\
\hline & Cervical corpectomy and fusion & $50-1000 \mathrm{~mL}$ \\
\hline & Transthoracic spine surgery & 200-5000 mL (non-tumor cases: $200-400 \mathrm{~mL}$ ) \\
\hline & Lumbar fusion and fixation & $250-1000 \mathrm{~mL}$ \\
\hline & Microdiscectomy & $25-100 \mathrm{~mL}$ \\
\hline & Craniotomy & $\begin{array}{l}50-500 \mathrm{~mL} \text { (meningioma and renal } \\
\text { cell are highly vascular) }\end{array}$ \\
\hline \multirow[t]{6}{*}{ Cardiothoracic surgeries } & Coronary artery bypass & $500-600 \mathrm{~mL}$ \\
\hline & Surgical valve replacement (aortic and mitral) & $300-400 \mathrm{~mL}$ \\
\hline & Heart transplant & $500-1500 \mathrm{~mL}$ \\
\hline & Lobectomy, pneumonectomy, wedge resection & $<500 \mathrm{~mL}$ \\
\hline & Heart-lung transplant & $500-2000 \mathrm{~mL}$ \\
\hline & Lung transplant: single; double & $500 \mathrm{~mL} ; 500-2000 \mathrm{~mL}$ \\
\hline \multirow[t]{4}{*}{ Vascular surgery } & Carotid endarterectomy & $100-200 \mathrm{~mL}$ \\
\hline & Aortic aneurysm repair: thoracic; abdominal (open) & $300-400 \mathrm{~mL} ; 500 \mathrm{~mL}$ \\
\hline & Acute aortic dissection & $400-800 \mathrm{~mL}$ \\
\hline & Infrainguinal arterial bypass & $200-300 \mathrm{~mL}$ \\
\hline \multirow[t]{8}{*}{ General surgery } & Esophagectomy & $300-800 \mathrm{~mL}$ \\
\hline & Sleeve gastrectomy or Roux en Y & $<500 \mathrm{~mL}$ \\
\hline & Gastrectomy: partial; total & $100-500 \mathrm{~mL} ;>500 \mathrm{~mL}$ \\
\hline & Whipple's procedure & $500-750 \mathrm{~mL}$ \\
\hline & Appendectomy & $<75 \mathrm{~mL}$ \\
\hline & Cholecystectomy & Minimal-250 mL \\
\hline & Renal transplant & $100-200 \mathrm{~mL}$ \\
\hline & Liver transplant & $\begin{array}{l}1500 \mathrm{~mL} \text { average (may require up to } \\
100 \text { units due to associated coagulopathy }\end{array}$ \\
\hline \multirow[t]{3}{*}{ Obstetrics \& gynecological } & Hysterectomy: abdominal; vaginal & $200-300 \mathrm{~mL} ; 100-200 \mathrm{~mL}$ \\
\hline & Radical hysterectomy & $500-1500 \mathrm{~mL}$ \\
\hline & Cesarean section: lower segment; classic & 750-1000 mL; 1000-2000 mL \\
\hline \multirow[t]{3}{*}{ Urological } & Transurethral resection or prostate (TURP) & $500 \mathrm{~mL}$ \\
\hline & Nephrectomy: simple; partial & $500 \mathrm{~mL} ; 1200 \mathrm{~mL}$ \\
\hline & Cystectomy & Minimal-1500 mL depending on extent \\
\hline \multirow[t]{3}{*}{ Otolaryngology } & Laryngectomy & $50-300 \mathrm{~mL}$ \\
\hline & Neck dissection & $200-400 \mathrm{~mL}$ \\
\hline & Thyroidectomy & $50-75 \mathrm{~mL}$ \\
\hline
\end{tabular}

Measures to Increase RBC Mass or Hemoglobin Blood transfusion still remains the default treatment for post-operative anemia and works rapidly. There are obvious benefits of quickly increasing the hemoglobin concentration in patients with chest pain, hemodynamic instability, or hypotension unresponsive to fluids. However, for the majority of patients, rapid correction is not indicated and, in fact, may be detrimental. The hazards of transfusion include immunomodulatory effects, risks of circulatory overload, transfusion reactions, and infective complications. The immunomodulatory effects of transfused blood include increased cancer recurrence, metastasis, and postoperative infection [2]. It has been well established that the restrictive strategy of targeting hemoglobin of $7 \mathrm{~g} / \mathrm{dL}$ is as effective and may be superior to the liberal strategy of targeting 
Table 2 Bleeding risk associated with common procedures $[8,9]$

High bleeding risk $\quad$ Low bleeding risk

\begin{tabular}{|c|c|}
\hline Neurological & Intracranial or spinal surgery \\
\hline Cardiac & Cardiac surgery (bypass, valve replacement) \\
\hline Vascular & Major vascular surgery (aortic aneurysm, vascular bypass) \\
\hline Thoracic & Lung resection \\
\hline Abdominal/pelvic & $\begin{array}{l}\text { Major abdomino-pelvic surgeries (pancreatic resection, } \\
\text { bowel resection, hepatobiliary, endometrial/ovarian } \\
\text { cancer resection) }\end{array}$ \\
\hline Orthopedic & $\begin{array}{l}\text { Major orthopedic surgeries (hip fracture, hip, knee } \\
\text { and shoulder arthroplasty) }\end{array}$ \\
\hline Otolaryngological & Major surgery of head and neck (cancer resection, reconstruction) \\
\hline Urological & Urologic surgery (radical prostatectomy, bladder resection \\
\hline Common biopsies & Kidney, liver, polypectomy \\
\hline Anesthesia techniques & Neuraxial (spinal, epidural) \\
\hline Ophthalmologic & Orbital decompression, retinal surgeries \\
\hline
\end{tabular}

Pacemaker and defibrillator implant placement, coronary angiography

Peripheral vascular stent placement

Cholecystectomy, hernia repair, hydrocele repair, colonoscopy with biopsy, hysteroscopy

Hand and foot surgery, arthroscopic surgery

Fiber optic laryngoscopy

Cystoscopy, hydrocelectomy

Dermatologic, thyroid, breast, lymph node

General

Cataract

hemoglobin of $10 \mathrm{~g} / \mathrm{dL}$ in critically ill patients [16]. This has also been studied in elderly patients with high cardiovascular risk where liberal transfusion did not reduce the rate of death or in-hospital morbidity compared with restrictive strategy [17]. The American Association of Blood Banks (AABB) in their guidelines in 2016 recommended adopting a policy for restrictive transfusion $(7$ to $8 \mathrm{~g} / \mathrm{dL})$ in stable hospitalized patients. These guidelines recommended a threshold of $<7 \mathrm{~g} / \mathrm{dL}$ in all surgeries except in cardiac surgery and orthopedic surgery patients where a threshold of $\sim 8 \mathrm{~g} / \mathrm{dL}$ was recommended [18]. More recently, an international conference on PBM released a consensus statement recommending a restrictive transfusion threshold as well. Some of these recommendations are summarized in Table 3 [19].

Iron deficiency remains common in post-operative period and should be corrected. However, in the post-operative period, oral iron is often not tolerated or absorbed. Hepcidin synthesis and release during surgery is increased which in turn inhibits intestinal iron absorption, making oral iron therapy largely ineffective. Intravenous (IV) iron is, therefore, preferred for correction. Both pre-operative and post-operative administration of IV iron with or without erythropoietinstimulating agents (ESA) has been found to be a safe and effective way for correcting anemia after a variety of major surgeries $[20,21]$. In patients undergoing major abdominal surgery, pre-operative intravenous iron was associated with a $60 \%$ reduction in the need for allogenic blood transfusion [21]. It was also associated with a shorter hospital stay, enhanced iron stores, and higher mean Hgb concentration 4 weeks after surgery [21]. An international consensus statement on the management of post-operative anemia recommends that, where possible, it should be administered using a single high dose preparation for the repletion of iron stores
[4]. Currently, six intravenous iron formulations are available in the USA [4, 22] (Table 4). Intravenous direct iron preparations have existed since 1940s but were feared as a large release of elemental iron caused severe adverse events (SAE) including anaphylaxis. In 1964, high molecular weight iron dextran which had a slower release of elemental iron gained popularity but still had a 1-2\% risk of SAE. In 1991, a different preparation, low molecular weight iron dextran was approved for widespread use as studies showed the dextran moieties of low molecular weight iron dextran were less immunogenic. However, it still carried a black box warning for anaphylaxis and currently requires a test dose. Many clinicians and health authorities still consider that IV iron is strongly associated with major side effects such as anaphylaxis, infection, or oxidative stress. However, these side effects appear not to be significant with the newer IV iron preparations [4]. One study in 2002 [23] concluded that compared to iron dextran, iron sucrose and iron gluconate are far less immunogenic because of their carbohydrate moiety. However, they release less elemental iron per dose and require multiple dosing. Ferumoxytol, another newer formulation caused significant hypotension when infused rapidly and hence carries a black box warning that recommends prolonged infusions over $15 \mathrm{~min}$. Ferric carboxymaltose is better tolerated and more effective than other intravenous iron preparations especially in treating inflammatory bowel disease-related anemia [24]. Recently approved ferric derisomaltose can be given as a single infusion with a similar safety profile as iron sucrose [25].

The choice of which formulation to use often depends on the institutional availability. It has long been suggested that patients with iron overload are at increased risk of infection. Data from meta-analyses and large observational studies showed that peri-operative IV iron did not increase post- 
Table 3 Recommendations for transfusion threshold [19]

\begin{tabular}{ll}
\hline Type of surgery & Recommendation; Hgb threshold \\
\hline $\begin{array}{l}\text { Non-cardiac surgery (excluding hip fracture) } \\
\text { in a hemodynamically stable patient }\end{array}$ & Restrictive; $<7 \mathrm{~g} / \mathrm{dL}$ \\
$\begin{array}{l}\text { Cardiac surgery } \\
\text { Hip fracture in patient with underlying cardiovascular } \\
\text { disease or other risk factors }\end{array}$ & Restrictive; $<7.5 \mathrm{~g} / \mathrm{dL}$ \\
$\begin{array}{l}\text { Critically ill but hemodynamically stable patient } \\
\text { Acute gastrointestinal bleeding in a } \\
\text { hemodynamically stable patient }\end{array}$ & Restrictive; $<8 \mathrm{~g} / \mathrm{dL}$ \\
\hline
\end{tabular}

operative infection or 30-day mortality rates in surgical patients. However, in the absence of definitive clinical data, it would seem logical to refrain from IV iron administration in the setting of acute infection [4].

Prevalence of vitamin B12 and folate deficiency in patients with anemia is low in peri-operative period. Nonetheless, when such deficiencies are noted, they should be corrected promptly. Patients undergoing gastric bypass surgery especially Roux-en-Y should have pre-operative assessment of vitamin B12 levels and any deficiency should be treated. Iron deficiency remains prevalent in this population and one study found that the rate of iron deficiency increased from $6 \%$ pre-operatively to $42 \%$ post-operatively in female patients [26]. This further reinforces the need to correct all nutritional deficiencies prior to elective surgery.

Erythropoietin-stimulating agents (ESA) are increasingly being used both in pre- and post-operative settings for correction of anemia along with iron supplementation. In addition to stimulating erythropoiesis in post-operative period, a single dose of ESA can also decrease serum levels of hepcidin. A Cochrane review of recombinant erythropoietin (rEPO) in patients with colorectal cancer failed to show any significant change in hemoglobin level with pre-operative use of rEPO, or a decrease in the number of patients receiving allogeneic blood transfusion [27]. However, a study of combined therapy of IV iron and recombinant human erythropoietin in anemic patients undergoing cardiac valve replacement surgery was associated with decreased length of stay, decreased blood transfusion, and improved survival [28]. Previously, a systematic review of erythropoietin use in patients undergoing orthopedic and cardiac surgery showed a reduction in the proportion of patients receiving allogeneic blood transfusions [29]. Potentially harmful effects include hypertension, and thrombotic and ischemic events.

For non-cancer patients with severe post-operative anemia and inflammation-induced blunted erythropoiesis, or those declining blood transfusion (for e.g., Jehovah's witness), consideration should be given to additional treatment with an ESA [4]. In fact, for a special population like Jehovah's witness, their beliefs mainly preclude blood transfusions and they are often willing to accept both IV iron and ESA. In a recent thought-provoking study in patients undergoing cardiac surgery, the authors used an ultra-short-term treatment of patients with intravenous iron, ESA, vitamin B12, and folic acid a day before surgery. This strategy was associated with a decrease in the need for RBC transfusion within 7 days and up to 90 days after surgery [30]. This may be a useful strategy for urgent and time-sensitive surgeries where optimization of pre-operative anemia is often not possible. It may also be a consideration in a patient's declining blood transfusion like Jehovah's witness.

Table 4 Different formulations of IV iron available in the USA [4, 16]

\begin{tabular}{|c|c|c|c|c|c|c|}
\hline Generic name & Iron dextran & $\begin{array}{l}\text { Sodium ferric } \\
\text { gluconate }\end{array}$ & Iron sucrose & Ferumoxytol & $\begin{array}{l}\text { Ferric } \\
\text { carboxymaltose }\end{array}$ & $\begin{array}{l}\text { Ferric derisomaltose (iron } \\
\text { isomaltoside) }\end{array}$ \\
\hline US brand name & Infed & Ferrilict & Venofer & FerraHeme & Injectafer & Monoferric \\
\hline Approval date & 1991 & 1999 & 2000 & 2009 & 2013 & 2020 \\
\hline Plasma half-life (h) & 20 & 1 & 6 & 15 & 16 & 20 \\
\hline Needs test dose & Yes & No & No & No & No & No \\
\hline Black box warning & Yes & No & No & Yes & No & No \\
\hline Single total dose infusion & Yes & No & No & No & No & Yes \\
\hline $\begin{array}{l}\text { Suggested dosage and } \\
\text { frequency (for } 1000 \mathrm{mg} \\
\text { deficit) }\end{array}$ & $\begin{array}{l}25 \mathrm{mg} \text { test dose } \\
\text { then } \\
1000 \mathrm{mg} \text { single } \\
\text { dose }\end{array}$ & $\begin{array}{l}125 \mathrm{mg} \text { IV up to } 8 \\
\text { doses }\end{array}$ & $\begin{array}{l}200 \mathrm{mg} \text { up to } 5 \\
\text { doses }\end{array}$ & $\begin{array}{l}510 \mathrm{mg} \text { every } \\
3-8 \text { days for } \\
\text { total } \\
2 \text { doses }\end{array}$ & $\begin{array}{l}15 \mathrm{mg} / \mathrm{kg} \text { every } \\
7 \text { days for } 2 \\
\text { doses }\end{array}$ & $1000 \mathrm{mg}$ single dose \\
\hline
\end{tabular}




\section{Conclusion}

Although the cause of post-operative anemia is multifactorial, it is often considered to be reflective of peri-operative blood loss. A targeted approach to correcting pre-operative anemia, minimizing peri-operative blood loss and establishing restrictive transfusion threshold and use of intravenous iron therapy are key components of management of post-operative anemia.

Open Access This article is licensed under a Creative Commons Attribution 4.0 International License, which permits use, sharing, adaptation, distribution and reproduction in any medium or format, as long as you give appropriate credit to the original author(s) and the source, provide a link to the Creative Commons licence, and indicate if changes were made. The images or other third party material in this article are included in the article's Creative Commons licence, unless indicated otherwise in a credit line to the material. If material is not included in the article's Creative Commons licence and your intended use is not permitted by statutory regulation or exceeds the permitted use, you will need to obtain permission directly from the copyright holder. To view a copy of this licence, visit http://creativecommons.org/licenses/by/4.0/.

\section{References}

1. Gomez-Ramirez S, Jerico C, Munoz M. Perioperative anemia: Prevalence, consequences and pathophysiology. Transfus Apher Sci. 2019;58(4):369-74

2. Clevenger B, Mallett SV, Klein AA, Richards T. Patient blood management to reduce surgical risk. Br J Surg. 2015;102(11): 1325-37 discussion 4.

3. Cata JP, Gottumukkala V. Blood transfusion practices in cancer surgery. Indian J Anaesth. 2014;58(5):637-42.

4. Munoz M, Acheson AG, Bisbe E, Butcher A, Gomez-Ramirez S, Khalafallah AA, et al. An international consensus statement on the management of postoperative anaemia after major surgical procedures. Anaesthesia. 2018;73(11):1418-31.

5. Jaffe RA, Schmiesing CA, Golianu B. Anesthesiologist's manual of surgical procedures. Fifth edition. ed. Philadelphia: Wolters Kluwer Health; 2014.

6. Douketis JD, Spyropoulos AC, Kaatz S, Becker RC, Caprini JA, Dunn AS, et al. Perioperative Bridging Anticoagulation in Patients with Atrial Fibrillation. N Engl J Med. 2015;373(9):823-33.

7. Doherty JU, Gluckman TJ, Hucker WJ, Januzzi JL Jr, Ortel TL, Saxonhouse SJ, et al. 2017 ACC Expert Consensus Decision Pathway for Periprocedural Management of Anticoagulation in Patients With Nonvalvular Atrial Fibrillation: A Report of the American College of Cardiology Clinical Expert Consensus Document Task Force. J Am Coll Cardiol. 2017;69(7):871-98.

8. Spyropoulos AC, Douketis JD. How I treat anticoagulated patients undergoing an elective procedure or surgery. Blood. 2012;120(15): 2954-62.

9. Kalra SK. Prevention of Venous Thromboembolism. In: Cohn SL, editor. Decision Making in Perioperative Medicine: Clinical Pearls: McGraw Hill; 2021. p. 53-61.
10. Callum JL, Waters JH, Shaz BH, Sloan SR, Murphy MF. The AABB recommendations for the Choosing Wisely campaign of the American Board of Internal Medicine. Transfusion. 2014;54(9):2344-52.

11. Bisbe E, Molto L. Pillar 2: minimising bleeding and blood loss. Best Pract Res Clin Anaesthesiol. 2013;27(1):99-110.

12. Franchini M, Marano G, Veropalumbo E, Masiello F, Pati I, Candura F, et al. Patient Blood Management: a revolutionary approach to transfusion medicine. Blood Transfus. 2019;17(3):191-5.

13. Yates J, Perelman I, Khair S, Taylor J, Lampron J, Tinmouth A, et al. Exclusion criteria and adverse events in perioperative trials of tranexamic acid: a systematic review and meta-analysis. Transfusion. 2019;59(2):806-24.

14. Fillingham YA, Ramkumar DB, Jevsevar DS, Yates AJ, Bini SA, Clarke HD, et al. Tranexamic Acid Use in Total Joint Arthroplasty: The Clinical Practice Guidelines Endorsed by the American Association of Hip and Knee Surgeons, American Society of Regional Anesthesia and Pain Medicine, American Academy of Orthopaedic Surgeons, Hip Society, and Knee Society. J Arthroplast. 2018;33(10):3065-9.

15. Task Force on Patient Blood Management for Adult Cardiac Surgery of the European Association for Cardio-Thoracic S, the European Association of Cardiothoracic A, Boer C, Meesters MI, Milojevic M, Benedetto U, et al. 2017 EACTS/EACTA Guidelines on patient blood management for adult cardiac surgery. J Cardiothorac Vasc Anesth. 2018;32(1):88-120.

16. Hebert PC, Wells G, Blajchman MA, Marshall J, Martin C, Pagliarello $\mathrm{G}$, et al. A multicenter, randomized, controlled clinical trial of transfusion requirements in critical care. Transfusion Requirements in Critical Care Investigators, Canadian Critical Care Trials Group. N Engl J Med. 1999;340(6):409-17.

17. Carson JL, Terrin ML, Noveck H, Sanders DW, Chaitman BR, Rhoads GG, et al. Liberal or restrictive transfusion in high-risk patients after hip surgery. N Engl J Med. 2011;365(26):2453-62.

18. Carson JL, Guyatt G, Heddle NM, Grossman BJ, Cohn CS, Fung MK, et al. Clinical Practice Guidelines From the AABB: Red Blood Cell Transfusion Thresholds and Storage. JAMA. 2016;316(19): 2025-35.

19. Mueller MM, Van Remoortel H, Meybohm P, Aranko K, Aubron C, Burger R, et al. Patient Blood Management: Recommendations From the 2018 Frankfurt Consensus Conference. JAMA. 2019;321(10):983-97.

20. Laso-Morales MJ, Vives R, Gomez-Ramirez S, Pallisera-Lloveras A, Pontes C. Intravenous iron administration for post-operative anaemia management after colorectal cancer surgery in clinical practice: a single-centre, retrospective study. Blood Transfus. 2018;16(4):338-42.

21. Froessler B, Palm P, Weber I, Hodyl NA, Singh R, Murphy EM. The Important Role for Intravenous Iron in Perioperative Patient Blood Management in Major Abdominal Surgery: A Randomized Controlled Trial. Ann Surg. 2016;264(1):41-6.

22. Munoz M, Gomez-Ramirez S, Martin-Montanez E, Auerbach M. Perioperative anemia management in colorectal cancer patients: a pragmatic approach. World J Gastroenterol. 2014;20(8):1972-85.

23. Michael B, Coyne DW, Fishbane S, Folkert V, Lynn R, Nissenson $\mathrm{AR}$, et al. Sodium ferric gluconate complex in hemodialysis patients: adverse reactions compared to placebo and iron dextran. Kidney Int. 2002;61(5):1830-9.

24. Aksan A, Isik H, Radeke HH, Dignass A, Stein J. Systematic review with network meta-analysis: comparative efficacy and tolerability of different intravenous iron formulations for the treatment of 
iron deficiency anaemia in patients with inflammatory bowel disease. Aliment Pharmacol Ther. 2017;45(10):1303-18.

25. Auerbach M, Henry D, Derman RJ, Achebe MM, Thomsen LL, Glaspy J. A prospective, multi-center, randomized comparison of iron isomaltoside 1000 versus iron sucrose in patients with iron deficiency anemia; the FERWON-IDA trial. Am J Hematol. 2019;94(9):1007-14.

26. Engebretsen KV, Blom-Hogestol IK, Hewitt S, Risstad H, Moum $\mathrm{B}$, Kristinsson JA, et al. Anemia following Roux-en-Y gastric bypass for morbid obesity; a 5-year follow-up study. Scand J Gastroenterol. 2018;53(8):917-22.

27. Devon KM, McLeod RS. Pre and peri-operative erythropoietin for reducing allogeneic blood transfusions in colorectal cancer surgery. Cochrane Database Syst Rev. 2009;1:CD007148.

28. Cladellas M, Farre N, Comin-Colet J, Gomez M, Merono O, Bosch MA, et al. Effects of preoperative intravenous erythropoietin plus iron on outcome in anemic patients after cardiac valve replacement. Am J Cardiol. 2012;110(7):1021-6.

29. Laupacis A, Fergusson D. Erythropoietin to minimize perioperative blood transfusion: a systematic review of randomized trials. The International Study of Peri-operative Transfusion (ISPOT) Investigators. Transfus Med. 1998;8(4):309-17.

30. Spahn DR, Schoenrath F, Spahn GH, Seifert B, Stein P, Theusinger $\mathrm{OM}$, et al. Effect of ultra-short-term treatment of patients with iron deficiency or anaemia undergoing cardiac surgery: a prospective randomised trial. Lancet. 2019;393(10187):2201-12.

Publisher's Note Springer Nature remains neutral with regard to jurisdictional claims in published maps and institutional affiliations. 